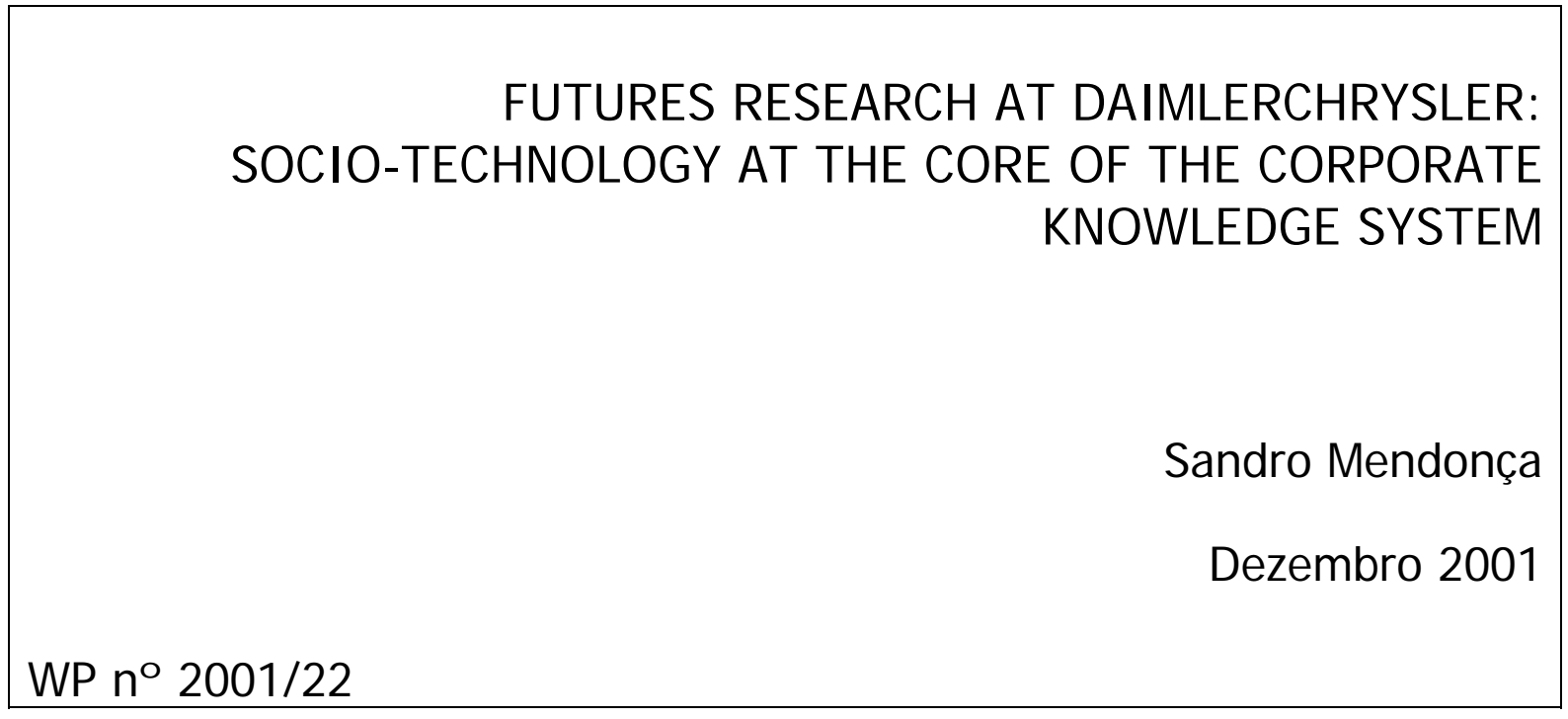

DOCUMENTO DE TRABALHO

WORKI NG PAPER 
D I N Â M I A centro de estudos sobre a mudança socioeconómica

\title{
FUTURES RESEARCH AT DAI MLERCHRYSLER: SOCIO-TECHNOLOGY AT THE CORE OF THE CORPORATE KNOWLEDGE SYSTEM
}

\author{
Sandro Mendonça*
}

WP $2001 / 22$

Dezembro 2001

\section{ÍNDEX}

1. INTRODUCTION

2. The Story of the Future Lab $\quad 2$

3. Strategic Foresight and Corporate Planning $\mathbf{5}$

4. The Scenario Methodology at DaimlerChrysler $\quad 7$

5. AN INTERPRETATION OF SCENARIOS AS SOCIO-TECHNOLOGY WITH A SOCIAL-SCIENCE BASE $\mathbf{1 3}$

6. CONCLUSIONS 14

$\begin{array}{ll}\text { REFERENCES } & 17\end{array}$

* The author would like to thank Frank Ruff, Senior Manager of STRG and social environment and trend analyst at Daimler-Chrysler AG, for his help and comments. Conversations with Manuel Mira Godinho and Ben Martin were also instrumental in the consolidation of my views. The author is a member of DINÂMIA, and lecturer at ISCTE. The author remains responsible for any error. 


\section{INTRODUCTION}

In today's globalising and turbulent economy the way to achieve long-term leading position has become an increasingly tough dynamic process. Because a company's market position is not safe for long if it systematically fails to keep up with the pace of change, sustaining competitive advantage is a continuous and restless task at the heart of which technological and organisational innovations prove fundamental. As in any other large business organisation, strategic planning at DaimlerChrysler (DC) is an activity of vital importance.

The creation and renovation of a company's competencies, i.e., its ability to master knowledge about production and distribution and its understanding of demand and users' needs, has become itself institutionalised as a business of a particular trade. Most of the world's leading corporations have a Research \& Development (R\&D) department where new science-based ideas and designs are tested and applied to the resolution of specific technological problems. Only more recently some large companies are carrying the internal division of labour a step further by establishing a new department or division exclusively devoted to socio-economic and strategic research. These units have the job of assessing the possible future directions of the organization in contrast with where the accumulation of competencies is leading.

In this contribution we supply a description of the ways in which Society and Technology Research Group (STRG), the research and consulting institution within the DaimlerChrysler business group, helps strategic policy-making through the scenario methodology. We also aim at producing more general comments about the implications of the scenario-building process for managerial competence. Specifically, we elaborate on the analogy between R\&D and futures research and argue that complex methodologies of interactive learning such as scenarios can be regarded as sociotechnology. We also point out the significant role social sciences can be play in the process of generating useful knowledge for corporate management.

The empirical base of this research is mainly composed by documentation provided by STRG and by an interview carried out with Frank Ruff, one of its senior managers. This evidence is compounded by reference to complementary data, namely from the case of Royal Dutch/Shell and its groupplanning unit.

DINÂMIA - CENTRO DE ESTUdOS SOBRE A MUdANÇA SOCIOECONÓMICA ISCTE, Av. das Forças Armadas, 1649-026 Lisboa, PORTUGAL Tel. 217938638 Fax. 217940042 E-mail: dinamia@iscte.pt 
The paper is organised as follows. We start by reviewing the history of STRG in the context of its parent company. In section 3, we proceed by making an account of the nature and development of the scenario methodology. We then describe the elementary steps and scenarios techniques carried out at STRG. Section 5 presents some views about the strategic role of scenarios in an innovating organisation and section 6 concludes.

\section{THE STORY OF THE FUTURE LAB}

In 1979 Daimler-Benz decided it was time to have a specialised function to foster strategic change. Rather than waiting for outside pressure to make adaptation unavoidable with high adjustment costs, the idea was to anticipate the unfolding of the forces that shape the business environment in order to gain strategic advantage over the competition. Since then the STRG unit has been in charge of assisting corporate planning, the "Future Lab" is its internal informal name. Its mission of enabling DC's business units and top management to make better decisions has involved monitoring the surrounding societal, political, economic and business environments and creating scenarios as a backdrop for evaluating strategic options for possible product innovations. In assisting the top managerial teams, STRG also takes into account the set of long-term socio-economic issues like the evolution of users' behaviour and consumer patterns that are likely become relevant for the future of the organisation. As Frank Ruff points out, the Senior Manager of Social Environment and Trend Research, a trained sociologist, having an in-house think-tank with such an ambitious focus is not typical of most companies.

The main users of the Society and Technology Research Group services are its partners from the divisions of the DaimlerChrysler Group: passenger cars with brands Mercedes-Benz, Smart, Chrysler, Jeep and Dodge; commercial vehicles with brands Mercedes-Benz, Freightliner and Sterling; DaimlerChrysler Services; DC Aerospace; Adtranz, and DC Central Divisions. The STRG also works for external customers, namely the DC suppliers and other firms and organisations that do not compete directly with the DC group.

According to Fortune magazine's Global 500 list, DaimlerChrysler became the second largest company in the world in terms of revenues in 1998. DaimlerChrysler's headquarters are divided 
between Stuttgart, Germany, and Auburn Hills, Michigan, USA. The DC group had a total workforce of 416500 employees world-wide in 2001, 28000 of which in R\&D. The company registers an average of 2,000 patents every year. At the time of merger it in 1998 was selling 4.5 million units passenger cars and commercial vehicles under the brands Mercedes-Benz, Chrysler, Plymouth, Jeep, Dodge, smart, Freightliner, Sterling, Setra. In spite of being concentrating in its automotive core business DC continues a major shareholder of Airbus and Adtranz. DaimlerChrysler Services (debis) AG, founded in Berlin in 1990, is one of the most recent companies in the group to become autonomous, its main activities being financial services and ICT services.

From Berlin and Palo Alto, California, STRG serves its internal and external customers. The research team is composed of 35 researchers. The team has a highly diversified international background, its elements coming from Germany, USA, France, Canada, Iran, Chile, Brazil, South Africa, Indonesia, South Africa. STRG also has a strength in its interdisciplinary capabilities including economics, sociology, history, psychology, urban planning, business administration, philosophy, physics, engineering, transportation and communication theory.

Having accumulated a vast amount of experience over nearly an hundred projects since its foundation, the STRG team sees itself acting as a knowledge broker whose objective is to transform a flood of information in the business environment into knowledge about the factors shaping tomorrow's markets and products (DaimlerChrysler 1999, p. 3). Undoubtedly the demand for this kind of consulting has increased in recent years. Factors like the ever-increasing pace of technological change and the unsettled configuration of the word political and commercial order have ridiculed all linear forecasts making planning a very complex enterprise. In this turbulent environment, STRG's role in the DC group is to enable the customers to have a pro-active policy attitude in face of uncertainty. The nature of STRG's activity is, therefore, to generate and use social science-based research to serve as foundations for strategic decisions concerning the development of future products, services and processes. The areas on which STRG keeps a close watch are: Lifestyles and social change; Information, communication and knowledge; Mobility and spatial development; Natural environment; Management and organisation.

In order to solve future-oriented policy puzzles, STRG integrates conventional business analysis tools with the client's specific needs to provide tailor-made solutions. This implies a high degree of 
communication and close collaboration with the promoters of the project. The extensive set of services offered by STRG are organised around the following methodological building blocks:

- scenarios;

- product assessment;

- conceptualisation of future consumer needs and desires;

- multimedia display of business environment and social trends;

- $\quad$ strategic options prioritisation;

- $\quad$ expert panel assembly on short notice;

- innovation processes design, organisation systems design;

- development of think tools to organise new forms of communication and decision-making.

\section{STRATEGIC FORESIGHT AND CORPORATE PLANNING}

Forecasting the future is an impossible task but an organisation can prepare for the uncertainties that lie in its path by trying to understand the trends and events that will conspire to compromise the company's trajectory. Foresight techniques such as the Scenario and Delphi methods do not aim at predicting the future. Instead, their aim is to understand the major forces shaping the future and frame a process of debate around the options to adapt and take advantage of the changing states of the world.

Traditional "economistic" forecasting techniques come short of an answer. As the Nobel Prize economist Wassili Leontief once put it, the problems found in forecasting are similar to trying to find out how a car's engine works by listening to the sound it makes. Both approaches do not carry the analyst very far, they barely scratch the surface of phenomena. Going beyond the mere extrapolation of historical time-series, scenario methods attempt to detect the underlying properties that propel the system into the future. In this way, sketching different future worlds is a method that allows the early identification of opportunities and risks associated with current business practices and also helps in 
the generation, development and evaluation of innovative ideas. STRG recognises the following biases in traditional forecast studies (Ruff 1999, p.10-1):

口 linear projection of trends;

- once-and-for all assessment of the systems causal dynamics;

u underestimation of speed of change in early stages of the basic innovations;

a overestimation of speed of incremental changes;

- neglect of bottlenecks in developmental processes;

- mistaking technological feasibility as marketability of an innovation;

口 under-representation of qualitative variables;

口 propensity to polarised risk-assessment.

Avoiding the serious costs of these analytical biases implies a departure from simplistic modelling techniques and patterns of linear causation. The challenge is therefore to go deeper and try to unveil the forces that push the system forward as a whole. In the course of such an approach the qualitative techniques and heuristic devices become of greatest utility. Of course, what is gained in relevance is lost in quantification. In the words of John Maynard Keynes, another famous economist, it is better to be approximately correct than rigorously wrong.

Putting the DC's case into a broader comparative perspective it can be argued that this company was effective in following the trend of increasing autonomy of strategic planning research among the world's largest corporations. Moreover, it was swift if seriously adopting scenario techniques after Shell's claims of its successful experience with scenario planning in the 1970's.

Shell is widely known to have been a pioneer in the introduction of scenarios in association with corporate planing. The introduction of the scenario approach at Shell happened with the constitution of the Group Planning unit in 1967. Shell had had several planning systems before the scenario unit and these used forecasting techniques with the objective of predicting the price of oil, the exchange rates, the rate of return of investment projects, etc. Already by the late $1960 \mathrm{~s}$, the poor predictive capacity of these quantitative techniques was generating dissatisfaction and allowing room for experimentation. These situation led to the development of a new generation of scenarios, the origins of which dated back to Second World War long-range planning studies having been subsequently 
improved by research carried out at RAND Corporation in the 1950s and the Hudson institute in the 1960's.

When the oil price crisis came with the Yon Kippur war in October 1973, of the world's largest oil companies, the "seven sisters", Shell is reported to have been the quickest to act and came out best. This event contributed to deeply entrenching the scenario approach in the company's strategic management process. Oil price crisis repeated in 1979 and 1985 and again Shell managers acted smoothly as if they were prepared for a price shock. In the words of Peter Holmes, Chairman of Shell at the time, quoted in a Shell official history book, the company was not "particularly hurt":

“we were not totally astonished. I mean, we didn't expect it; but we made a provision for it ... We asked our planners to have a look at a possible decline scenario. They were very good at working out scenarios - the whole Shell system works on that basis." (Howarth, 1997, pp.348-9)

Today, scenarios are an integral part of the strategic planning process developed at those units. Observers attribute a large part of this popularity to Shell's success (Georgantzas and Acar, 1995, p.27). According to a recent study carried out by The Futures Group, a company of the Deloitte \& Touche consulting group, $82 \%$ of American companies with revenues over US $\$ 10$ billion had an organised Business Intelligence Unit in 1997 (The Futures Group, 1997). Also according to The Futures Group, 63 out of 100 top the US corporations are estimated to be using scenario techniques to help crafting strategic plans.

\section{THE SCENARIO METHODOLOGY AT DAIMLERCHRYSLER}

The philosophy behind scenario building at STRG is one of creating a realistic picture of possible consequences of past and present choices by tracking down the direction and rhythm of development of these possibilities. Following STRG's own definition, scenarios are "[d]escriptions of alternative futures designed to order a set of strategic actions. They are neither predictions nor strategies. Rather, they offer a way to evaluate risks, clarify the rules of the game, anticipated key moments of change, and identify tradeoffs when approaching strategic decisions." (DaimlerChrysler, 1999, p.7)

At STRG the scenario approach evolved in reference to seven guiding principles: 
- Decision-orientation - the goals of the customer are central, researching a company's business environment as a strategic aim is not an end in itself;

- Future-orientation - the reference point is the future, where today's decisions will have impact;

- Interdisciplinary - cross-fertilisation among different sources of expertise increases creativity and diminishes the likelihood of developing "blind spots";

- Holism - thinking in terms of systems instead of isolated events increases awareness for unexpected connections and interactions;

- Methodological pluralism - tackling complex social problems require tools that shed light from different angles;

- Interactiveness - there are no "ready-made" solutions, customers have to be involved in the generation of options;

- Methodological innovation - new environments and organisational forms demand new generations of instruments and procedures.

As Eckard Minx, director of STRG, puts it "scenarios are of help in the preparation of decisions, they do not however replace them. Instead, they make it particularly clear what has been forgotten or suppressed and what no number of facts can ever change: we must decide - against a background of our normative issues - even and particularly when we cannot be completely sure.” (Minx 1999, p. 17) In other words, scenario analysis can be seen as a flexible methodology that creates a forwardlooking attitude without trapping the decision-maker into a pre-established/common-sense vision of what might happen. It is assumed that the future is not settled and it can be partially affected by the long-term consequences of well-crafted policies.

According to STRG's own views (Ruff, 2001) typical foresight exercises performed in private sector as compared to public organisations are generally narrower in the time scope (2-15 years) and have a duration of about 3 months to a year. The major outputs coming out of those projects are:

- Stocking up ideas aimed at the anticipation of future developments;

- Topic-focused communication process;

- Creation of a shared frame of reference across departments and professions mind-sets;

- Systemic thinking (networking different kinds of knowledge)

- Orientation towards future options for action. 
The act of scenario building is just the beginning of the process of organisational change. Futures research and the planning process are intertwined. By presenting alternatives in which the contrast between the outcomes of actual and desirable trajectories can be depicted more clearly scenarios provide a basis for strategic conversation. Here lies a central message in scenario thinking: scenarios are a process of structured communication. The intangible nature of this output of futures-research in opposition to the concrete nature of the scenario documents can themselves be misleading. It is this process of focused discussion with regard to decision-making that makes scenarios critical for the organisation's success.

The technical scenario approach at DC's Future Lab is the following:

\section{Figure 1}

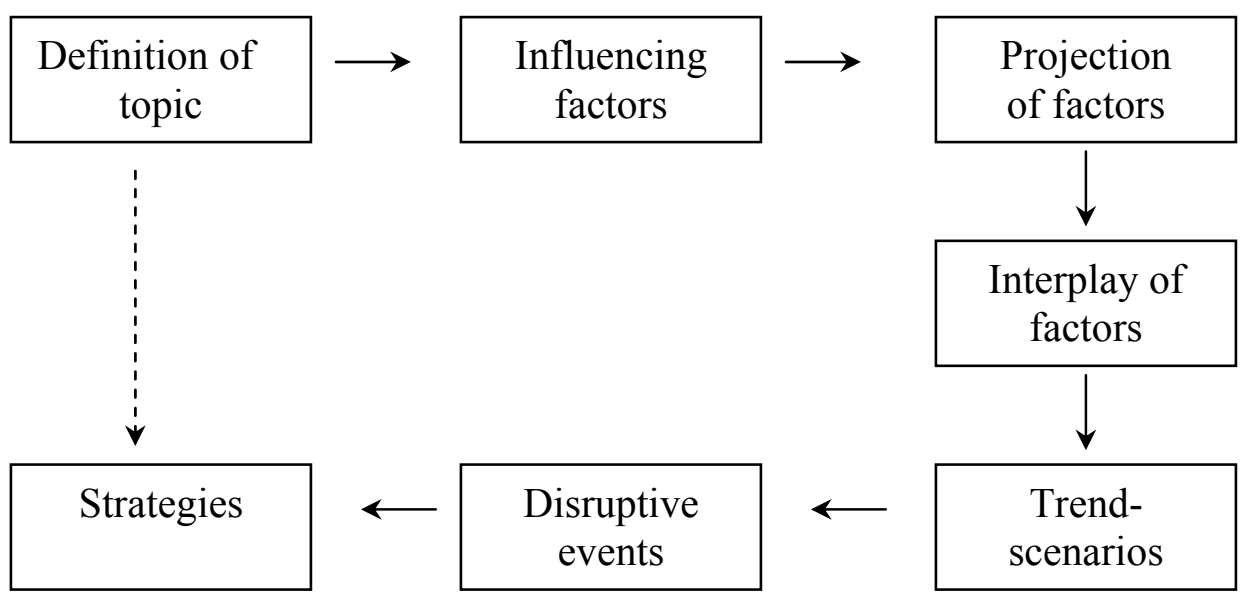

Source: Ruff (1999)

What is the issue to analyse?

The process of building scenarios often starts with a worry in the managers or the analysts' minds. In order to make the most of scenario methodology, the topic to address should be relevant in business context in the time horizon of ten to fifteen years. 
Which factors have an impact on the issue?

The determination of the relevant factors that influence the system is a process of reduction and division of factors into several categories. Cross-cutting with the usual classification of factors into Political, Economic, Social, Technological and Ecological (PESTE) descriptors, the Future Lab methodology introduces its own complementary analysis. First there is the split between premises and descriptors:

$\checkmark$ Premises are very robust trends that will very likely take one definite path of development (alternative developments are unlikely);

Descriptors are factors that can take multiple paths of development allowing also for different kinds of interrelationships among each other giving rise to particular system patterns.

Then the descriptors themselves are then broken down into three sub-categories:

- Global descriptors (i.e. oil price);

- Regional descriptors (i.e. EU regulations);

- Segment specific descriptors (i.e. acquisition policy of airlines).

How might the influential factors develop?

Furthermore, descriptors are also submitted to a process of selection by which the influential factors with highest importance and highest uncertainty have to be focused in particular. This stage is one of prioritisation and an importance/uncertainty chart of is used in the analysis. On the one hand, highlighting the most likely projections of the most important and uncertain descriptors will yield the Base scenario. On the other hand, by combining variations of the possible trends of highly influential factors Alternative scenarios can be derived. The projections of the high importance/uncertainty factors call for some narrative account of why and how alternative trends could happen and some appreciation of the relative probability of their occurrence. Also as result of the analysis low impact factors cease to be focused in scenario construction and high importance/low uncertainty factors are taken as a common basis in both Base and Alternative scenarios.

Which cross-impacts exist?

DINÂMIA - CENTRO DE ESTUdOS SOBRE A MUdANÇA SOCIOECONÓMICA ISCTE, Av. das Forças Armadas, 1649-026 Lisboa, PORTUGAL Tel. 217938638 Fax. 217940042 E-mail: dinamia@iscte.pt 
Mapping the interrelationships between the descriptors is usually done by means of a cross-impact analysis, by which the power of each factor to influence the others is assessed. This analysis is coupled with driver-driven analysis to cluster together factors that network with the others in a similar way. In this way a descriptor that strongly influences other factors more than is influenced by them is called a driver. Conversely, a descriptor that is more influenced by others than influencing them is a driven factor. A descriptor that is both a strong driver and strong driven is an ambivalent or critical factor, some changes in these kind of factors can influence the system tremendously. These analyses emphasise the system dynamics in which the topic is embedded.

Which consistent images of the future can be generated?

From all the alternative pictures of the future which can be generated at least two should be selected according: a "trend scenario" type and an extreme scenario maximising the differences to the trend scenario. Another alternative scenario with high relevance to current business conditions can also be included.

Which events could lead to discontinuities in trends?

Disruptive events or wild cards are unpredictable single events or combinations of events with great impact. Events of this kind have the power to act like "turning points" of history, marking a moment where the direction and rhythm of long lasting trends are changed.

Which actions fit with the scenarios?

In the final stage of scenario analysis recommendations should be presented. The different scenarios are like basic core statements about the business environment exposing the organisation's strengths and weaknesses in the presence of change. The opportunities and risks facing the company in different scenarios can and should be translated into an action agenda.

\section{AN INTERPRETATION OF SCENARIOS AS SOCIO-TECHNOLOGY WITH A SOCIAL-SCIENCE BASE}

DINÂMIA - CENTRO DE ESTUdOS SOBRE A MUDANÇA SOCIOECONÓMICA ISCTE, Av. das Forças Armadas, 1649-026 Lisboa, PORTUGAL Tel. 217938638 Fax. 217940042 E-mail: dinamia@iscte.pt 
We submit that one useful way of understanding the role of scenarios within a business organisation is trough the notion of socio-technology. We use the term socio-technology to designate the social mechanisms of internal and external coordination that define and are defined by business organisations. Examples of these are formal organisational structures (eg, the multi-divisonal form, the lean organisation), networking arrangements (eg, alliances, join-ventures), etc. In our context, the scenario methodology, being a structured process for interactive learning that involves a complex set of sub-techniques, is by itself a socio-technology.

Moreover, scenarios are a special kind of socio-technology for they are a knowledge production mechanism that partially draws on social science techniques and insights. Here comparison with $R \& D$ is comes naturally ones mind. Technological innovation within a company comes out from laboratory research as well as learning-by-doing in the day-to-day management of operations. Conversely, strategic knowledge of how to run a particular business comes out of lessons drawn from practice in the company that are blended with and systematised by the help of formally acquired skills of the organisation's leadership. The scenario department can fuel this learning process by injecting socio-economic research based on social sciences theories, taxonomies and evidence-based patters in a well-defined framework of debate working as a catalyst of business innovations. We argue, therefore, that scenarios, as well as the Delphi method or other sophisticated techniques of foresight and marketing management, helping to make sense of the business environment, can be regarded as social science-based socio-technology.

One benefit of this view of the process promoting change in the internal social relations and external positioning of the company is that calls for a more detailed account of the factors influencing competitiveness. Not only natural sciences influence the companies trajectory through the applied ideas developed in the R\&D department but applied social science research can have an impact as well. Therefore, dynamic social capabilities and the sources of those capabilities are important for explaining differences in corporate performance. The conceptual model bellow applies the wellknown, and much abused linear model of innovation to our case.

Figure 2

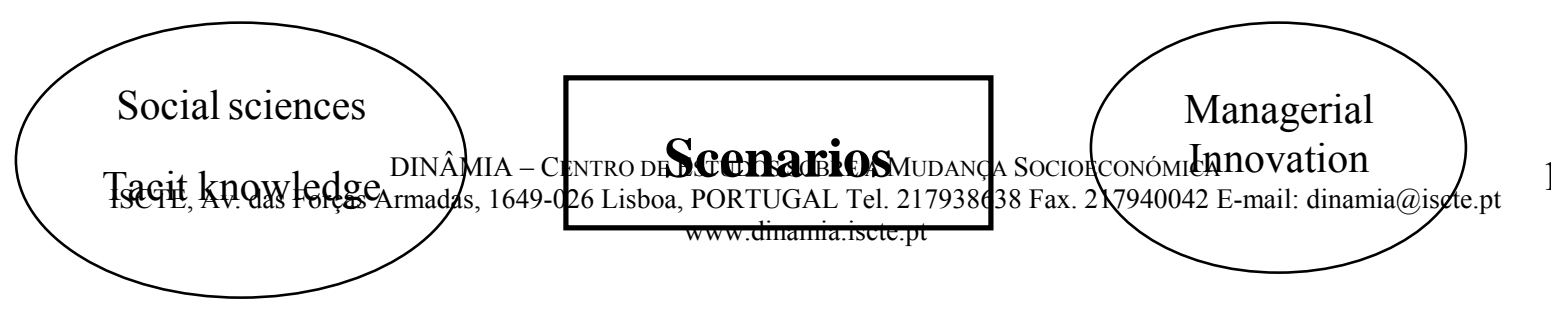


Source: Adapted from Mendonça (2001b)

Our interviewee Frank Ruff shows to be aware of the value of the inspiration and discipline that can be gained from social sciences when he says that "the knowledge base used in scenario building should be very diverse ... we especially promote social scientific perspectives." Data collected from Shell through interviews with group planners and through inspection of confidential reports also confirms that inputs from social sciences are routinely used in scenario building, namely from economic history and the economics of technical change (Mendonça, 2001b).

\section{CONCLUSIONS}

The task of the futures researcher is like being high up on the top mast of a ship and keeping a close watch on the horizon. In that privileged position he or she might be capable of spotting weak signals of the obstacles ahead and unexpected new ways forward. Looking ahead is not an easy task due to the veil of uncertainty shrouding where the future paths might lead. Looking ahead is not enough because the responsibility to make decisions remains in the hands of the top officials of the company. The job of futures research is to ensure that top management is involved in the foresight process so that it can take an informed decision. Scenarios do not replace decisions, they are employed to facilitate them and they need to be well communicated.

Long-term research into the future can serve as a robust basis for decision-making. In this sense, futures research contributes to the minimisation of corporate risk by allowing the test of how alternative courses of action could perform in changing market conditions. Such a qualitative and intellectual enterprise provides the company with an early warning system that can be a key variable for success in a turbulent environment. Installing a future-orientation in a company empowers it with an autonomous engine of organisational change. 
Relevant scenarios are linked to the decision-making process. Scenarios are most effective if they are problem-oriented, if the spectrum of alternative future worlds is significantly wide and if a clear meaning for the company' future emerges from the chains of events. These are necessary conditions for igniting a fruitful discussion within a company. An intangible benefit of scenarios is allowing for a departure from old ways of thinking and decision-making routines and biases. The dissemination of the scenario results is therefore crucial.

Top management needs reports in tune with their cognitive framework. Mind-sets must be challenged carefully otherwise the results of scenario exercises are not completely understood or can be rejected altogether. This implies a more than a passive role of the customers. In order to have a lasting effect in strategic decisions scenario planning must involve the project promoters from the beginning. Other important vehicles for the success of scenario planning are team mix in terms of gender and professions and nationality, collaboration with external experts and think-tanks, use of narrative techniques and visualisation. Working and re-working scenarios on such a basis confers increased chances of acceptance of uncertainty by policy-makers. The best scenario for scenario analysis is the one in which research has a real and positive impact in the life of the company, meaning that scenarios can be a lever for innovation and learning in the organisation.

Scenarios are not a simple problem-solving tool to arrive at optimal answers, they are more like an iterative process, a technology of a social kind. Scenarios are a complex methodology that articulates multiple techniques to deal with complex systems and evolving socio-economic patterns. Scenario analysis draws strongly on social science knowledge, both at the level of the methods employed and at the subject level. Scenarios act as a translator device of the opinion of the participants and of the findings of social theory making dispersed information and knowledge useful for corporate management.

Scenario planning is a process of intellectual creative destruction. It changes established individual decision-making habits and visions of the business environment. The institutionalisation of systematic future research promotes the adaptation of corporate strategy to a turbulent world. In the same way as with R\&D academic ideas are found to play a role in scenario building. With this kind of socio-technology not only new information is generated but also organisational learning is fostered, leading to potential organisational and strategic innovations. 
Futures ReseARCh AT DAIMLERChrysLeR:

SOCIO-TECHNOLOGY AT THE CORE OF THE CORPORATE KNOWLEDGE SYSTEM

\section{REFERENCES}

DaimlerChrysler

Berlin, Palo Alto, Society and Technology Research Group, 1999

Georgantzas, N.C. and W. Acar

Scenario-Driven Planning

London: Greenwood Publishing Group, 1995

Howarth, S.

A Century in Oil - The 'Shell' Transport and Trading Company 1897-1997

London: Weidenfeld \& Nicolson, 1997

Minx, E.

Building Bridges: How to cope with the gap between today and tomorrow

Forschung und Technologie (FT4/G), DaimlerChrysler, 1999

Ruff, F.

Scenarios in Integrated Assessment: Principles, methods and experiences with scenario planning in a business context

Paper presented at the ICIS Summer Course, September 6th, 1999

Ruff, F.

Society and technology foresight for corporate strategy: The experience of Daimler-Chrysler

Paper presented at the United Nations Industrial Development Organization (UNIDO) conference

Technology Foresight for Central and East European (CEE) countries and Newly Independent States (NIS), 4-5 April 2001.

The Futures Group

Extroverts or Introverts II - Executive Summary

Online at http://www.tfg.com/pubs/docs/cs-sumry.html, 1997

This article draws on papers originally published as:

Mendonça, S. (2001a), 'Futures research at the driver's seat: Scenario planning at DaimlerChrysler', in Van Asselt, M., J. Rotmans and S. Greeuw (eds), Puzzle-solving for Policy: A Provisional Handbook for Integrated Assessment, International Centre for Integrative Studies, University of Maastricht, (2001) pp. 133-144

Mendonça, S. (2001b), 'Scenarios as a social science-based technology: Evidence from Royal Dutch/Shell', in T. Stevenson, E. Massini, A. Rubin \& M. Lehmann-Chadha (eds), The Quest for the Futures: A Methodology Seminar in Futures Studies, Selections from the methodology seminar in futures studies, Turku, Finland, pp. 94-112. 